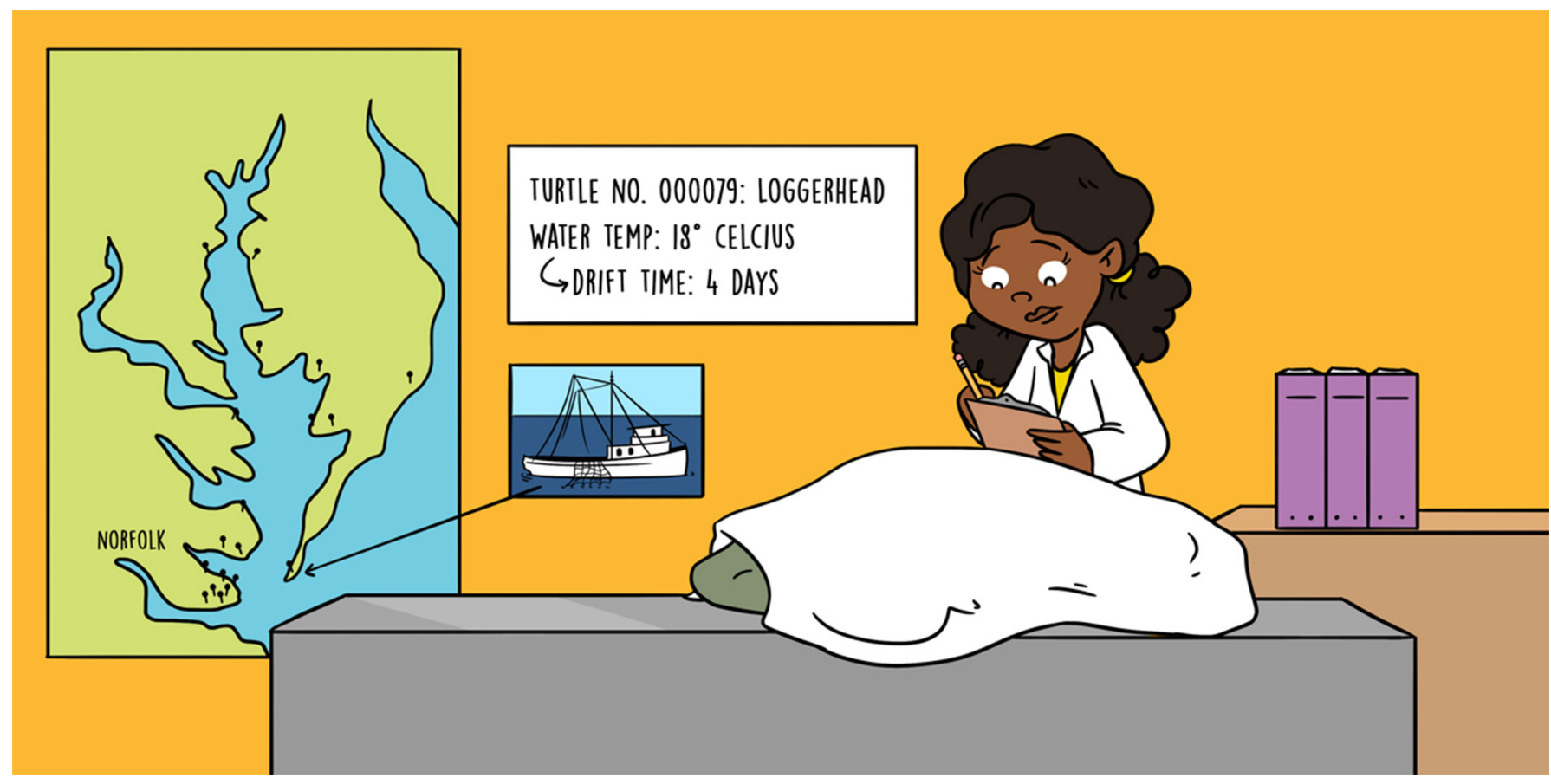

\title{
VIRGINIA BEACHED SEA TURTLE SURVEY
}

\section{Elyse Boudin ${ }^{1 *}$, Bianca Santos ${ }^{2 *}$, Frédérique Carcaillet ${ }^{1 *}$ and David Kaplan ${ }^{2 *}$ \\ ${ }^{1}$ MARBEC, University of Montpellier, CNRS, Ifremer, IRD, Montpellier, France \\ ${ }^{2}$ Virginia Institute of Marine Science, College of William \& Mary, Gloucester Point, VA, United States}

YOUNG REVIEWER:

ROHAN

AGE: 10
Sea turtles around the world are threatened with extinction, largely due to human activities. To better protect sea turtles, we need to improve our understanding of the activities that threaten them. However, we often do not know the cause of sea turtle deaths, making it difficult to help protect them. This is the case in the Chesapeake Bay, USA, where hundreds of dead sea turtles are found washed up on beaches each year. In this study, researchers investigated these events, known as sea turtle strandings, to better understand why sea turtles in this region are dying. First, they carried out experiments to predict when and where sea turtles died at sea. This information was then used to identify potential causes of sea turtle mortality. The results of the study suggest that high sea turtle mortality occurs at the entrance of the Bay, where many human activities take place.

\section{SEA TURTLES}

If you could dive and visit all the seas of the world, you would see a large number of animals and plants. They would all be different; 
Figure 1

There are seven living sea turtle species, shown here in comparison with an average adult human and an extinct sea turtle species, archelon, to show their relative size (illustration from the National Aquarium of Baltimore https://www aqua.org/blog/2015/ April/oceans-seven).

\section{SPECIES}

A group of similar organisms that can breed together.

\section{MORTALITY}

Death.

\section{STRANDED}

Washed up on beaches, dead.

\section{憵NATIONAL AQUARIUM。}

Turtles come in all shapes and sizes

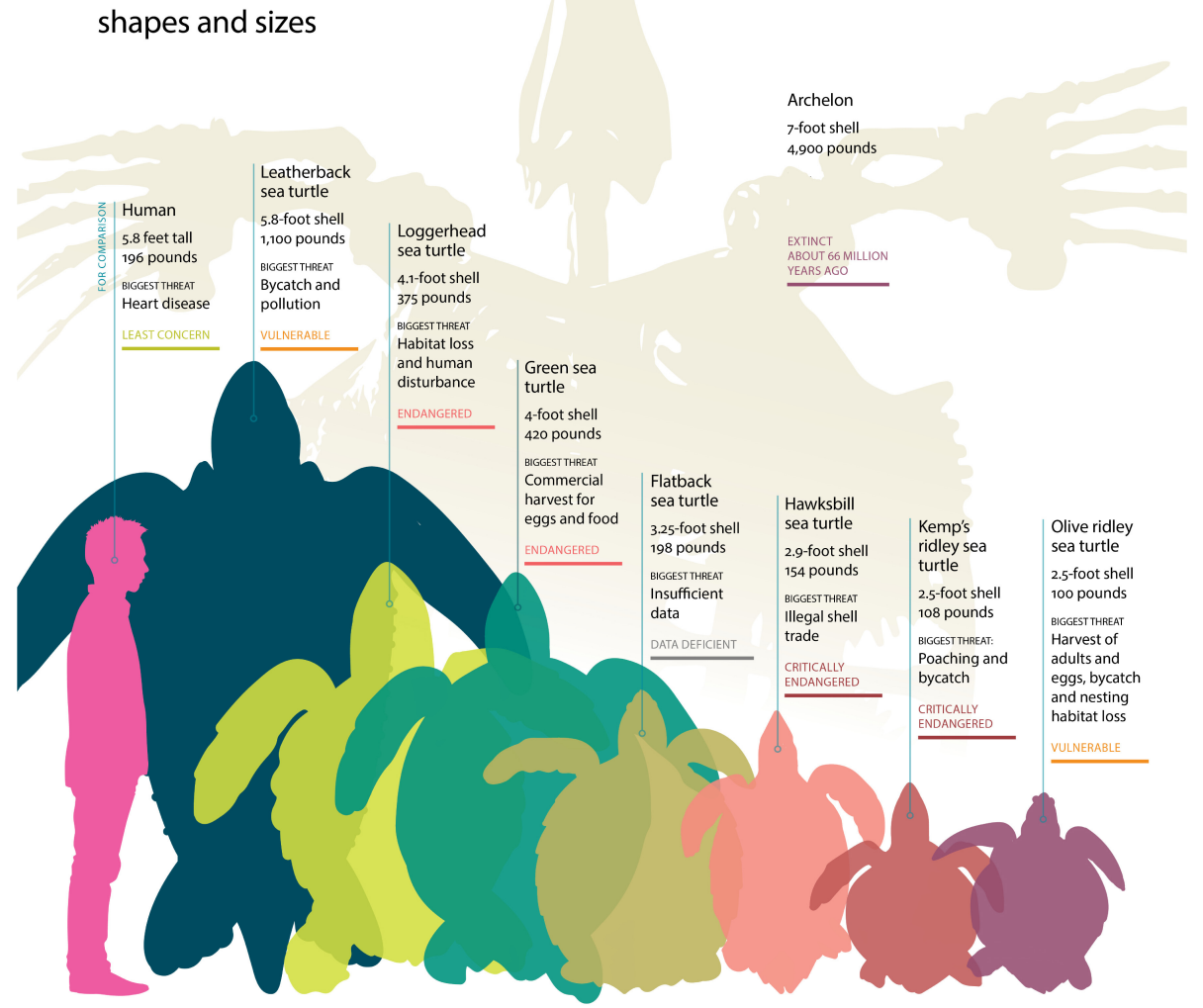

Figure 1

some very large and others tiny, some with dark colors and others with very bright colors. You could also find yourself face-to-face with a sea turtle. There are seven living species of sea turtles found worldwide: the leatherback sea turtle, the green sea turtle, the loggerhead sea turtle, the hawksbill sea turtle, the Kemp's ridely sea turtle, the olive ridely sea turtle and the flatback sea turtle (Figure 1). Unfortunately, these turtles are becoming more and more rare and, over time, some sea turtle species have even become extinct, including archelon, the largest sea turtle ever documented. Today, sea turtles are threatened with extinction due to human activities, including pollution, intensive fishing, ship strikes, climate change, and many others. To protect them, it is necessary to better understand the habitat use of sea turtles and define the threats to these species.

To help protect sea turtles, researchers carry out investigations to better understand the causes of sea turtle death, also known as mortality. Dead sea turtles are sometimes found washed up, or stranded, on beaches. Although the turtles may sometimes have injuries on them providing clues as to what may have killed them, often there are little or no traces on their bodies to help scientists understand why they died. This is what usually happens in the case of stranded 
Figure 2

Map of the Chesapeake Bay, USA (@) Google Maps).

\section{BACTERIA}

Microscopic organisms present nearly everywhere on Earth; some are dangerous and can induce infections and other are essential for life, as in the decomposition process.

\section{DECOMPOSITION}

Process in which a dead plant or animal is reduced to smaller. microscopic pieces by bacteria and other organisms.

\section{CARCASS}

A dead animal body.

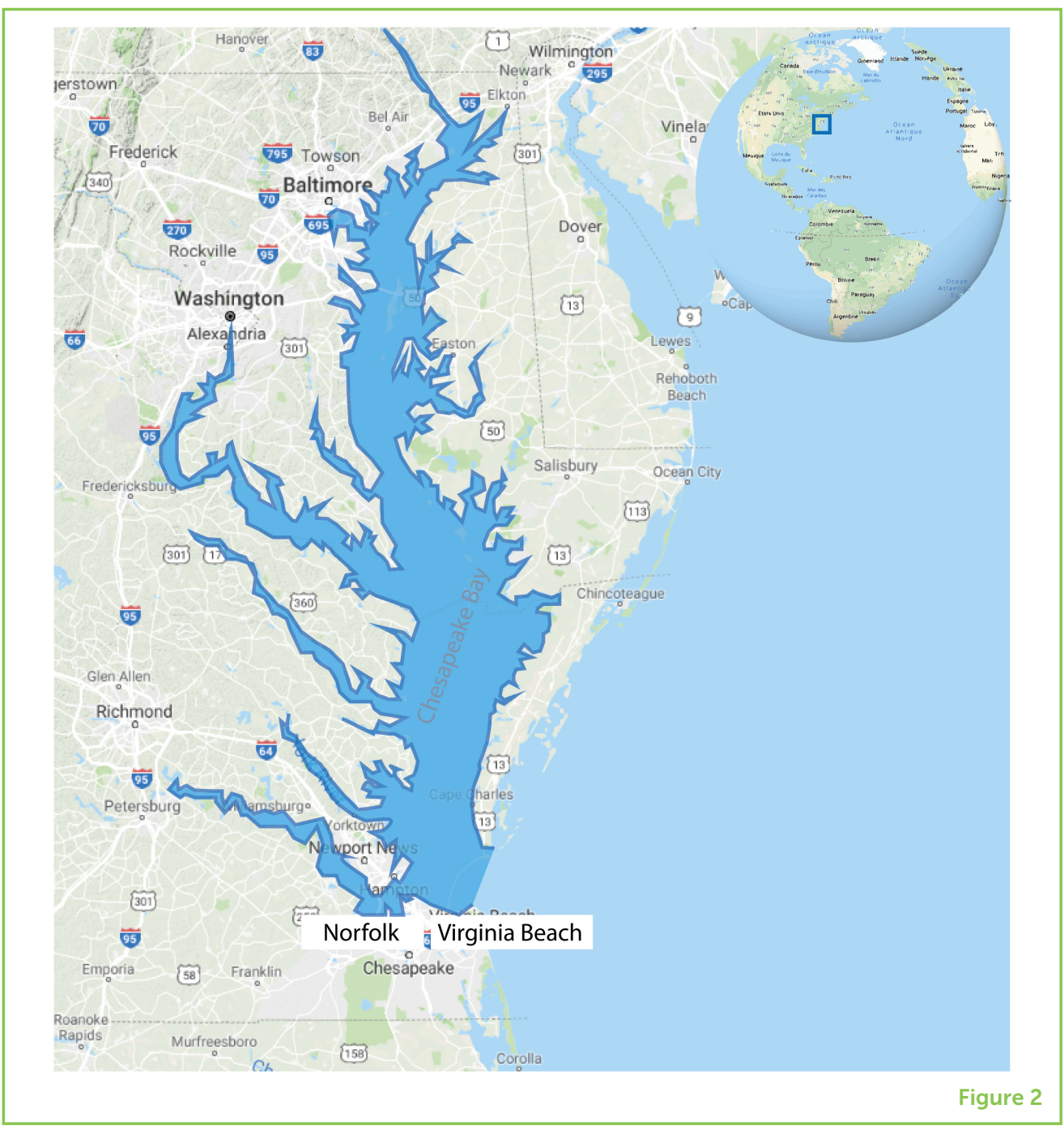

turtles found on the beaches of the Chesapeake Bay in Virginia, located in the eastern United States (Figure 2).

To better understand these stranding events and identify possible causes of mortality, we wanted to determine the area of the bay in which the beached turtles had died. With this information, we could look at things going on in those areas, such as fishing and boating activities, to try and determine what threatens sea turtles in this region. To first determine where and when the turtles died, we had to conduct experiments. Let us take a closer look at what was done!

\section{WHEN?}

When an animal dies, its body changes in appearance. It will gradually disappear as it is eaten by other animals and bacteria. This process is called decomposition. When a sea turtle dies, the first thing that happens is that the body of the turtle, known as a carcass, sinks to the bottom of the sea floor. However, the bacteria in its intestines 
Figure 3

Decomposition time of a sea turtle in warmer-temperature (left) and cooler-temperature (right) waters. In this experiment, dead sea turtle carcasses floated to the sea surface about 1 day after death in warmer water $\left(28^{\circ} \mathrm{C}\right)$ and remained floating for 2 days before sinking. However, in cooler water (below $20^{\circ} \mathrm{C}$ ), it took 2 days after death for sea turtle carcasses to float, at which point they remained floating for 10 days before sinking (C)Elyse Boudin).

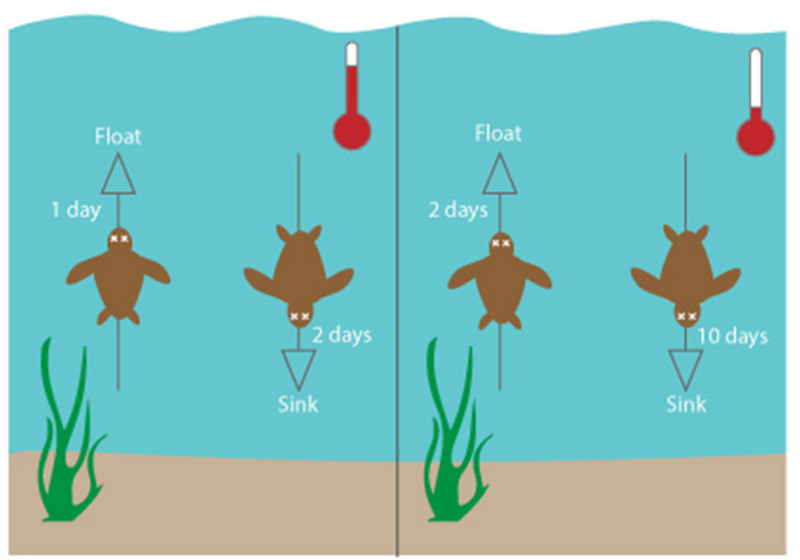

Figure 3

continue to live and produce gases, gradually making the body swell. Like a balloon filled with air, the body floats and rises to the sea surface. But, as the bacteria continue to decompose the body, the carcass will eventually develop holes and let out the gases that kept it on the surface. It sinks again and disappears to the bottom of the sea permanently.

The turtles found stranded on Virginia's beaches arrived floating. They had not yet released the gases they contained, otherwise they would have sunk and remained at the bottom of the sea without reaching the beach. Since we ultimately wanted to understand why these sea turtles died, we first needed to figure out where and when they died. Importantly, we needed to estimate how long the sea turtle carcasses spent floating at sea after they died and before they stranded. To estimate this, we first had to determine how long it takes for a sea turtle carcass to float after death and how long it can remain floating before sinking permanently.

To do this, we monitored the decomposition of eight dead sea turtles in waters of different temperatures. We made daily observations to see how many days passed before the bodies started to float and then how many more days it took for the bodies to decompose to the point when they sank permanently. We noticed that the warmer the water temperature was, the faster the sea turtle carcasses decomposed: in warm, summer water of about $28^{\circ} \mathrm{C}$, the bodies began to float after about 1 day, then sank permanently after floating for just 2 days. However, in colder, spring or fall waters below $20^{\circ} \mathrm{C}$, the carcasses rose to the surface after 2 days and remained floating for about 10 days before releasing their gases and sinking (Figure 3)! Why this difference? It is because bacteria like heat, and they will break down the turtle's body more quickly in warmer temperatures than in cooler temperatures. 
In summary, using the water temperatures and times observed in the experiment, we were able to estimate when each of Virginia's stranded sea turtles died at sea.

\section{WHERE?}

Now that we had an idea of when the stranded sea turtles died, the next step was to try to determine the place of death. It is necessary to know where the turtles died to potentially find out what killed them. For example, death could be due to a collision with a tourist boat or fishing boat. By knowing the turtle's place of death, researchers can check whether there are a lot of boats in that location, and then possibly find solutions to allow for boats and turtles to share the water area safety.

When a turtle is found stranded, it is impossible to know where it came from unless you retrace the path taken by its body since its death. When a sea turtle carcass floats, it drifts with currents and winds, just like a floating piece of plastic or wood would do, until it lands on the beach. Therefore, to predict this floating pathway, we must look at how the currents and winds transported the carcass as it floated on the sea surface. Other researchers had already made measurements to determine the effect of ocean currents on the trajectory of sea turtle carcasses. However, sea turtles have big shells that stick out of the water, meaning their movements are influenced by winds as well. No measurements had previously been taken regarding the effect of winds on sea turtle carcasses. We therefore conducted an experiment to determine the role played by winds in the trajectory of sea turtle carcasses.

How did we do it? We equipped floating turtle carcasses, which drift according to both ocean currents and winds, with GPS units. We also put GPS units on buckets, which barely exceed the water line and thus only drift with currents (Figure 4). Then we dropped the GPS-equipped carcasses and buckets off in different parts of the Chesapeake Bay and observed their trajectories. Looking at the results, we found that the turtle carcasses and buckets did not move in the same way. The turtle carcasses, which protrude from the water, are pushed by winds, while the buckets, which do not protrude, cannot be pushed by the winds. That means that winds play an important role in the path taken by a floating sea turtle carcass. Therefore, to find the place where the stranded turtles died, we had to consider not only the strength and direction of the currents over the previous days, but also the winds.

\section{SOLVING THE MYSTERY OF THE SEA TURTLES}

Each year, mainly in June, more than a hundred young loggerhead sea turtles are found stranded on the beaches of the Chesapeake 
Figure 4

An experiment was conducted to determine the role of winds on the trajectories of turtle carcasses. (Left) researchers equip a floating turtle carcass with a GPS (@D. Malmquist/VIMS). (Top right) $A$ bucket equipped with a GPS (CBianca Santos). (Bottom right) $A$ floating turtle carcass equipped with a GPS (CD. Malmquist/VIMS).

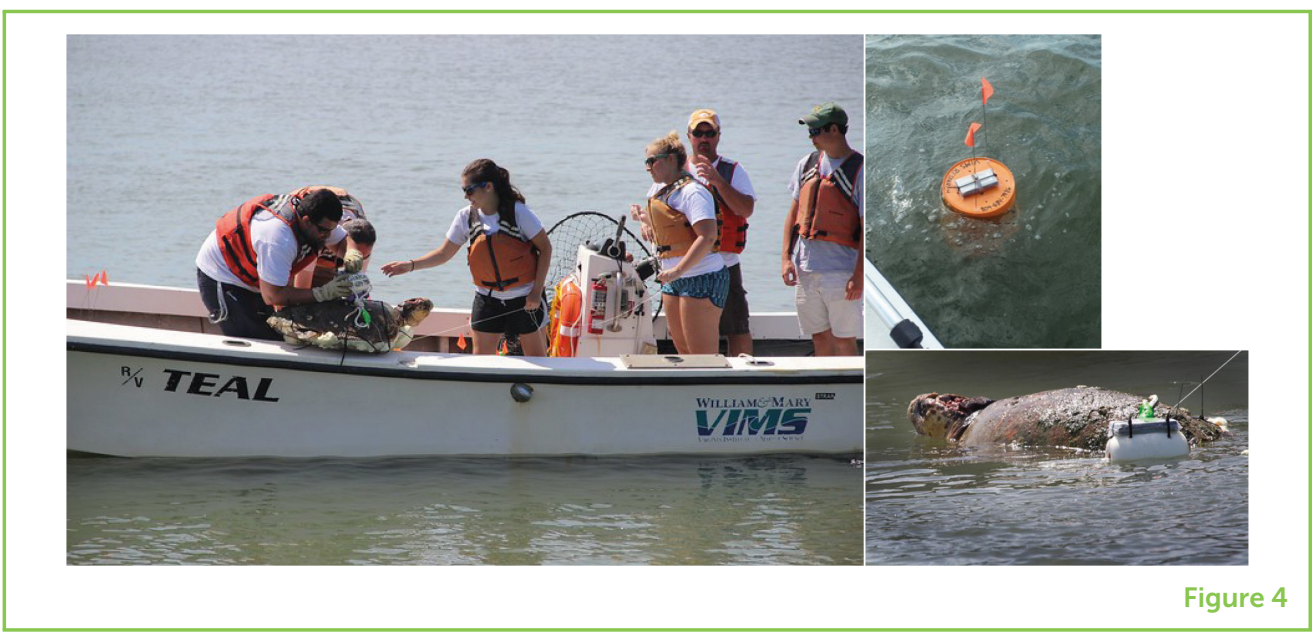

Bay. Using all of the information gathered by these experiments, we created a computer program to predict the paths likely taken by these turtle carcasses. According to these predictions, many sea turtles are believed to have died around the entrance of the bay, near the cities of Norfolk and Virginia Beach (Figure 2), which is an area widely used by humans for fishing and recreational activities.

Sea turtles face many dangers at sea, but they can be hard to study and protect, because they spend a lot of time in the open ocean where humans cannot reach them. Therefore, sea turtles that strand on local beaches where scientists can study them provide an important opportunity to investigate the threats that sea turtles face. The data and methods from this study give researchers a better idea of where sea turtle deaths are happening, and this research is one way to help protect the marine turtles that use the Chesapeake Bay each year. Knowing that many of these turtles die near the cities of Norfolk and Virginia Beach, the people working to preserve species and their habitats can try to remove or reduce threats in these areas. For example, they can establish rules for fishing and boat traffic, create a protected area, or work to educate the public.

Sea turtle strandings do not only happen in the Chesapeake Bay, but occur all over the world. Therefore, this research can also be used to help predict where sea turtles died at sea in many other areas of the world. In addition to sea turtles, other marine animals, such as dolphins and whales, can also die and end up stranded on local beaches. Scientists can use methods similar to those described in this study to investigate the locations of mortality for these animals, as well. With research like this, we can help protect the marine animals that live in our oceans.

\section{ORIGINAL SOURCE ARTICLE}

Santos, B. S., Kaplan, D. M., Friedrichs, M. A. M., Barco, S. G., Mansfield, K. L., and Manning, J. P. 2018. Consequences of drift and carcass 
decomposition for estimating sea turtle mortality hotspots. Ecol. Indicat. 84:319-36. doi: 10.1016/j.ecolind.2017.08.064

SUBMITTED: 13 September 2019; ACCEPTED: 12 March 2020;

PUBLISHED ONLINE: 07 April 2020.

EDITED BY: Mahasweta Saha, Plymouth Marine Laboratory, United Kingdom

CITATION: Boudin E, Santos B, Carcaillet F and Kaplan D (2020) Virginia Beached Sea Turtle Survey. Front. Young Minds 8:38. doi: 10.3389/frym.2020.00038

CONFLICT OF INTEREST: The authors declare that the research was conducted in the absence of any commercial or financial relationships that could be construed as a potential conflict of interest.

COPYRIGHT @ 2020 Boudin, Santos, Carcaillet and Kaplan. This is an open-access article distributed under the terms of the Creative Commons Attribution License (CC BY). The use, distribution or reproduction in other forums is permitted, provided the original author(s) and the copyright owner(s) are credited and that the original publication in this journal is cited, in accordance with accepted academic practice. No use, distribution or reproduction is permitted which does not comply with these terms.

\section{YOUNG REVIEWER}

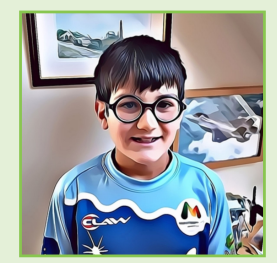

\section{ROHAN, AGE: 10}

I am interested in airplanes, engineering, Richard Trevithick, Isambard Kingdom Brunel, dinosaurs, mixoplankton and other mixotrophs, the deep sea, Lego. I enjoy reading science fiction (like 20,000 Leagues under the Sea), fantasy, and non-fiction. I like kayaking, cycling, and hockey.

\section{AUTHORS}
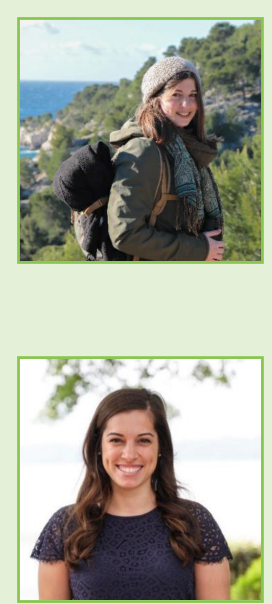

\section{ELYSE BOUDIN}

Elyse Boudin is finishing a master's degree in Ecology Engineering at the University of Montpellier. This work was a part of her master's internship at the Marine Biodiversity Exploitation and Conservation laboratory (MARBEC). She wants to work in the environment and sustainable development education field, to create a bridge between researchers and young people. *elyse.boudin@gmail.com

\section{BIANCA SANTOS}

Bianca Santos is a Ph.D. student in the Emmett Interdisciplinary Program in Environment and Resources at Stanford University. She earned her M.S. in Marine Science at the Virginia Institute of Marine Science, where she studied causes of sea turtle mortality in the Chesapeake Bay. Her research interests lie in developing innovation science-based solutions to reduce the harm of human activities and conserve protected marine species. *bianca.santos1128@gmail.com 


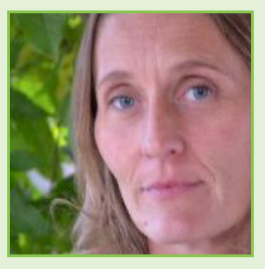

\section{FRÉDÉRIQUE CARCAILLET}

Dr. Frédérique Carcaillet is a senior lecturer in Aquatic Ecology at the University of Montpellier in France, where she mainly teaches in Masters of Ecology and Environmental Science Communication. Her research includes ecosystem function, science communication, and environmental education. She runs science animation film workshops to teach students how to communicate science to the general public. https://www.youtube.com/channel/UCdMXIvXqFZxiSFtsnFUQiZg/videos. *frederique.carcaillet@umontpellier.fr

\section{DAVID KAPLAN}

David M. Kaplan is currently a researcher at the French Institute for Research in Development (IRD). His research focuses on assessing the effects of different forms of spatial and non-spatial management on marine populations. One particularly important aspect of his research uses models and analyses of fisheries and marine ecosystem data to predict the impacts of marine protected areas. This way he can determine where and when it is best to close marine areas to human activities, such as fishing. *david.kaplan@ird.fr 